Bond University

Research Repository

\title{
Emergency care workload units: A novel tool to compare emergency department activity
}

Gedmintas, Audra; Bost, Nerolie; Keijzers, Gerben; Green, David; Lind, James

Published in:

EMA - Emergency Medicine Australasia

DOI:

10.1111/j.1742-6723.2010.01322.x

Licence:

Other

Link to output in Bond University research repository.

Recommended citation(APA):

Gedmintas, A., Bost, N., Keijzers, G., Green, D., \& Lind, J. (2010). Emergency care workload units: A novel tool to compare emergency department activity. EMA - Emergency Medicine Australasia, 22(5), 442-448.

https://doi.org/10.1111/j.1742-6723.2010.01322.x

\section{General rights}

Copyright and moral rights for the publications made accessible in the public portal are retained by the authors and/or other copyright owners and it is a condition of accessing publications that users recognise and abide by the legal requirements associated with these rights.

For more information, or if you believe that this document breaches copyright, please contact the Bond University research repository coordinator. 
Gedmintas, A., Bost, N., Keijzers, G., Green, D. and Lind, J. (2010). Emergency care workload units: A novel tool to compare emergency department activity. Emergency Medicine Australasia, 22(5), 442-448.

\section{Introduction}

Emergency Departments (EDs) are chaotic, busy working environments. ${ }^{1}$ The number of patients presenting to the ED can be accurately measured by electronic records, however there is a paucity of literature relating to the workload these patients generate. Traditionally within Australia, public health funding bodies have used various methods to determine budget, equipment and staffing requirements within the ED. These include utilizing attendance figures and historical financial data to determine departmental workload. This approach has several limitations. Firstly, attendance figures do not take into account the complexity or acuity of the patient, and secondly, budgeting based on previous expenditure does not take into account any increase in patient population or complexity of presentation. As a result budgets based on this method may lead to an inequality of resource distribution across different hospitals.

We therefore identified the need for a simple, easily implemented tool that is able to compare different EDs' actual workloads. It is envisaged that the proposed tool be used to distribute budget, staffing, equipment and resources across EDs in Australia in a more equitable way than is currently practiced. 


\section{Methods}

The proposed tool utilises existing data on patient acuity, disposition, numbers of patients and the individual costing of each presentation to estimate workload of the department. This calculated estimate is transferred to a new proposed unit; the emergency care workload unit (ECWU).

The ECWU tool was developed using the Australasian Triage Scale (ATS), ${ }^{2}$ disposition data for all presenting patients to hospital EDs and the National Hospital Cost Data Collection (NHCDC) Round 12 (2007-2008). ${ }^{3}$ Historical data from the computer software program EDIS (emergency department information system, isoft ED module: version 10) of the 27 largest public hospitals in Queensland were utilised to demonstrate the applicability of the tool. All datasets used are publicly accessible.

The ATS categorises patients into five groups of time related urgency. It was originally developed in 1993 as the National Triage Scale (NTS) which was a modification of the earlier Ipswich Triage scale. $)^{4}$ The Australasian college of Emergency Medicine in its 2006 policy document states that the scale directly relates triage code with a range of outcome measures (inpatient length of stay, ICU admission, mortality rate) and resource consumption (staff time, cost) ${ }^{2}$. Patients are grouped into categories of acuity according to their presenting complaint, current physiological condition and past medical history. A definitive time frame that a patient should be assessed and treated by ED staff has been attributed to that triage category. Table 1 summarises the five groups. 
Table 1: Triage categories

\begin{tabular}{cc}
\hline Triage category & Time to be seen \\
\hline 1 & immediately \\
\hline 2 & 10 mins \\
\hline 3 & 30 mins \\
\hline 4 & 60 mins \\
\hline 5 & 120 mins \\
\hline
\end{tabular}

Within Australia minimal research has been done looking at measurement of workload and resource consumption related to triage scale with the emergency department. Previous studies have examined nursing staff requirements using individual patient characteristics to determine workload per patient and thereby determining workload of ED nursing staff, ${ }^{5,6}$ but no Australian studies have been found that identified broader tools to estimate ED budget, staffing and resource requirements.

In Canada however, a few studies have in fact found correlation between triage scale and resource, staffing workload and cost. The CTAS (Canadian emergency triage and acuity scale) is based on the Australasian triage scale but has been altered to suit the Canadian population. ${ }^{7,8}$

Anderson et al in the Canadian Journal of Emergency Medicine noted that while there was marked variation in the distribution of time taken by physicians to see individual patients within each triage category, there was a significant increase In physician work time to see higher acuity patients with each category becoming increasingly more time consuming. ${ }^{9}$

Another study by Ma et al looked at the cost of resource consumption within each triage category in the paediatric population. Resource consumption was 
measured in terms of use of laboratory, microbiological, and diagnostic imaging. This study did not examine workload of Emergency physicians but did add a fixed cost of nursing time to each patient. They observed that in 16,661 patients the Paediatric Canadian triage and acuity scale (Ped- CTAS) correlated well with resource utilisation for patient management within the ED. ${ }^{10}$

Furthermore a study conducted in Alberta, Canada looked at the use of a web based triage decision support tool and found excellent predictive validity for resource utilisation and ED costs across close to 30,000 patients. ${ }^{11}$

We felt while these studies are based overseas it was fair to correlate their triage system with the Australian system and relate triage category to workload of doctors and cost of presentation. We used these premises to develop this tool..

Each patient within a triage category will generate an individual workload. A more urgent triage category is given to the more acute or critical patient and will incur a higher amount of resource consumption and greater workload. This is demonstrated in the NHCDC Australian government initiative. ${ }^{3}$ Information is gathered from hospitals nationwide, to provide an estimated costing of various hospital presentations according to Diagnosis Related Groupings (DRG). The document attributes a cost to an individual presentation related to their triage category and admission status. This initiative is published annually in the NHCDC Australian reference manual. ${ }^{3}$

Table 2 shows the NHCDC cost data for each triage category that is further subdivided into either admitted or non admitted patients. An ATS 1 admitted patient 
equates to a \$1170 AUD cost, which is approximately six times higher than the cost of an ATS 5 non admitted patient.

Table 2: From NHCDC Round 12. Average cost per ED patient presentation across Australia (Victorian hospitals excluded)

\begin{tabular}{ccc}
\hline Triage category & Admitted vs. Discharged & $\begin{array}{c}\text { Average cost } \\
\text { (AUD) }\end{array}$ \\
\hline 1 & Admitted & 1170 \\
\hline 2 & Admitted & 640 \\
\hline 3 & Admitted & 544 \\
\hline 4 & Admitted & 443 \\
\hline 5 & Admitted & 241 \\
\hline 1 & Discharged & 701 \\
\hline 2 & Discharged & 492 \\
\hline 3 & Discharged & 416 \\
\hline 4 & Discharged & 311 \\
\hline 5 & Discharged & 184 \\
\hline \multicolumn{3}{c}{ DNW } \\
\hline \multicolumn{2}{c}{ Total } & 31 \\
\hline \multicolumn{2}{c}{ Average Cost/ ED patient } \\
\hline
\end{tabular}

An admission is defined as a patient who has been assessed and managed within the ED and subsequently goes through a bed booking process to be admitted to an inpatient unit. This implies transfer (or intention to transfer) of the patient to a ward bed, under the care of an inpatient team within the hospital. ${ }^{12}$ Patient discharge refers to a presentation where the emergency assessment and management process result in the patient's discharge from the ED (eg. home). Patients who die in the ED are included in the discharge data. ${ }^{12}$

Patients who do not wait for assessment by a medical officer (DNW) are defined as a presentation to an ED after the patient has undergone a registration process (acknowledgement of arrival). The triage process may have taken place, however the 
patient decides to leave before further assessment and management can be undertaken. The patient's departure may not be known by ED staff. ${ }^{12}$

The cost of a patient's presentation represent staff work time, equipment and sundry resource use related to a patient presentation to an ED. A higher cost suggests that the workload is higher for these patients as the resource consumption is greater. Table 2 shows the cost calculated of a DNW. These costs are used as an approximate measure of workload defined in Emergency Care Workload Units (ECWUs).

There are a number of steps to calculate the final ECWUs.

1. The cost of a DNW is subtracted from the gross cost of each of the triage categories, leading to a net cost per triage category. This cost for a DNW can be seen as an unavoidable facility cost as every patient that enters the ED undergoes a registration process and is included in the total workload. Therefore the cost of a DNW represents a fixed amount of work (and cost) each patient will generate regardless of disposition or triage category.

2. A cost weight ratio is then calculated. The cost weight ratio is the net triage category cost, divided by the cost of the reference category (ATS 5 discharged). This provides the ratio of the cost of any category and the category with the lowest cost. The reference category of the discharged ATS 5 represents one (1) ECWU. (See Table 4)

Examples of calculations of ECWUs are shown in Figure 1. Figure 1 provides an example of how to calculate the ECWUs for a category 3 admitted patient. 
Cost of Cat 3 (Admitted) - DNW cost/ Cost of Cat 5(Discharged)-DNW cost $=\mathrm{x}$ (ECUs)

544 AUD - 31 AUD / 184 AUD - 31 AUD = 3.35 ECUs

Figure 1: Calculation of ECUs for a triage category 3 admitted patient

This is the peer reviewed version of the following article:

Gedmintas, A., Bost, N., Keijzers, G., Green, D., \& Lind, J. (2010). Emergency care workload units: A novel tool to compare emergency department activity. EMA - Emergency Medicine Australasia, 22(5), 442-448, which has been published in final form at https://doi.org/10.1111/j.1742-6723.2010.01322.x. This article may be used for non-commercial purposes in accordance with Wiley Terms and Conditions for Use of Self-Archived Versions 
Table 3 demonstrates the calculated ECWUs for all triage-disposition categories

Table 3: ECWUs per Triage category and Admission status as outlined in steps 1 and 2

\begin{tabular}{|ccccc|}
\hline $\begin{array}{l}\text { Triage } \\
\text { category }\end{array}$ & $\begin{array}{l}\text { Admitted vs } \\
\text { Discharged }\end{array}$ & $\begin{array}{l}\text { Average cost } \\
\text { (AUD) }\end{array}$ & $\begin{array}{l}\text { Minus DNW } \\
\text { (AUD) }\end{array}$ & $\begin{array}{l}\text { Average cost -DNW } \\
\text { divided by ATS 5 - } \\
\text { Discharged }\end{array}$ \\
\hline 1 & Admitted & 1170 & 1139 & 7.44 ECU \\
\hline 2 & Admitted & 640 & 609 & 3.98 ECU \\
\hline 3 & Admitted & 544 & 513 & 3.35 ECU \\
\hline 4 & Admitted & 443 & 412 & 2.69 ECU \\
\hline 5 & Admitted & 241 & 210 & 1.37 ECU \\
\hline 1 & Discharged & 701 & 670 & 4.38 ECU \\
\hline 2 & Discharged & 492 & 461 & 3.01 ECU \\
\hline 3 & Discharged & 416 & 385 & 2.52 ECU \\
\hline 4 & Discharged & 311 & 280 & 1.83 ECU \\
\hline 5 & Discharged & 184 & 153 & 1.00 ECU \\
\hline & DNW & 31 & & \\
\hline
\end{tabular}

ATS 5 - discharged is reference group

3. The number of annual presentations for each triage-disposition category in the ED are multiplied by the calculated ECWU per triage-disposition category.

This leads to a total number of ECWUs for that ED, which summarises the annual workload.

Table 4 illustrates data from one Queensland hospital calculated into ECWUs.

Table 4: Total ECWUs over a 12 month period in one Queensland ED

\begin{tabular}{|ccccc|}
\hline $\begin{array}{c}\text { Triage } \\
\text { Category }\end{array}$ & $\begin{array}{c}\text { Admitted vs } \\
\text { Discharged }\end{array}$ & $\begin{array}{c}\text { Hospital X } \\
\text { Number of } \\
\text { presentations } \\
\mathbf{2 0 0 8}\end{array}$ & $\begin{array}{c}\text { Average cost - } \\
\text { DNW divided by } \\
\text { CAT 5 Non } \\
\text { Admitted }\end{array}$ & $\begin{array}{c}\text { Total } \\
\text { ECUS }\end{array}$ \\
\hline 1 & Admitted & 575 & 7.44 & 4281 \\
\hline 2 & Admitted & 4,879 & 3.98 & 19420 \\
\hline 3 & Admitted & 9,295 & 3.35 & 31166 \\
\hline 4 & Admitted & 2,191 & 2.69 & 5900 \\
\hline 5 & Admitted & 125 & 1.37 & 172 \\
\hline 1 & Discharged & 84 & 4.38 & 368 \\
\hline 2 & Discharged & 3504 & 3.01 & 10558 \\
\hline 3 & Discharged & 20568 & 2.52 & 51756 \\
\hline 4 & Discharged & 17639 & 1.83 & 32281 \\
\hline 5 & Discharged & 2496 & 1.00 & 2496 \\
\hline Total & & 61,356 & & 158396 \\
\hline
\end{tabular}




\section{Results}

To illustrate how EDs can be compared, we applied this tool to a selection of deidentified EDs within hospitals representing different regions and population bases in the state of Queensland. Table 5 shows the calculated total ECWUs for six EDs in 2008. It demonstrates that although ED 3 assesses a similar number of patients per year as ED 2 (34498 and 34787), the latter has a greater number of ECWUs. This number reflects the higher acuity of the patient presentations and therefore the higher workload of that ED. 
Table 5: ECWUs calculated for 6 de-identified hospitals in Queensland

\begin{tabular}{|c|c|c|c|c|c|c|c|c|c|c|c|c|c|c|}
\hline $\begin{array}{c}\text { Triage } \\
\text { Categories }\end{array}$ & $\begin{array}{l}\text { Admitted(A)vs. } \\
\text { Discharged(D) }\end{array}$ & ECUs & ED(1) & $\begin{array}{c}\text { ECU } \\
\text { per } \\
\text { category }\end{array}$ & ED(2) & $\begin{array}{c}\text { ECU } \\
\text { per } \\
\text { category }\end{array}$ & ED(3) & $\begin{array}{c}\text { ECU } \\
\text { per } \\
\text { category }\end{array}$ & ED(4) & $\begin{array}{c}\text { ECU } \\
\text { per } \\
\text { category }\end{array}$ & ED(5) & $\begin{array}{c}\text { ECU } \\
\text { per } \\
\text { category }\end{array}$ & $\operatorname{ED}(6)$ & $\begin{array}{l}\text { ECU per } \\
\text { category }\end{array}$ \\
\hline 1 & $\mathrm{~A}$ & 7.4 & 21 & 156 & 30 & 223 & 4 & 30 & 225 & 1675 & 92 & 685 & 313 & 2330 \\
\hline 2 & A & 3.9 & 1027 & 4088 & 1293 & 5147 & 233 & 927 & 3000 & 11941 & 2648 & 10540 & 1117 & 4446. \\
\hline 3 & A & 3.3 & 7931 & 26592 & 7589 & 25445 & 3477 & 11658 & 13138 & 44051 & 21670 & 72658 & 4345 & 14568 \\
\hline 4 & A & 2.6 & 19903 & 53595 & 10121 & 27254 & 12188 & 32820 & 10678 & 28754 & 21304 & 57368 & 4973 & 13391 \\
\hline 5 & A & 1.3 & 6838 & 9385 & 1794 & 2462 & 14742 & 20234 & 2329 & 3197 & 2862 & 3928 & 20753 & 28484 \\
\hline 1 & $\mathrm{D}$ & 4.3 & 254 & 1112 & 285 & 1248 & 40 & 175 & 998 & 4370 & 358 & 1568 & 11444 & 50114 \\
\hline 2 & $\mathrm{D}$ & 3.0 & 1998 & 6020 & 3588 & 10811 & 437 & 1317 & 4154 & 12516 & 2747 & 8277 & 18228 & 54922 \\
\hline 3 & $\mathrm{D}$ & 2.5 & 6627 & 16676 & 6915 & 17400 & 1532 & 3855 & 9678 & 24353 & 7536 & 18963 & 2318 & 5832 \\
\hline 4 & D & 1.8 & 3029 & 5543 & 2982 & 5457 & 1486 & 2719 & 1932 & 3536 & 2137 & 3911 & 8152 & 14918 \\
\hline 5 & D & 1.0 & 212 & 212 & 190 & 190 & 359 & 359 & 123 & 123 & 108 & 108 & 269 & 269 \\
\hline Total & & & 47840 & 123380 & 34787 & 95638 & 34498 & 74095 & 46255 & 134516 & 61462 & 178006 & 71912 & 189277 \\
\hline
\end{tabular}


In Queensland approximately $80 \%$ of funding is determined based on historical funding, and approximately 20\% is based on case mix funding using Queensland health data costings. ${ }^{13}$ The historical funding data for different de-identified hospitals within Queensland are shown in table 6 together with the individually calculated ECWUs for 2008.

Table 6: Calculated funding for the 6 de-identified Queensland hospitals in AUD per ECWU

\begin{tabular}{|crrc|}
\hline Hospital & $\begin{array}{c}\text { Historical } \\
\text { funding in } \\
\text { 000's AUD }\end{array}$ & $\begin{array}{c}\text { ECU's } \\
\text { (2008) }\end{array}$ & $\begin{array}{c}\text { AUD per } \\
\text { ECU }\end{array}$ \\
\hline 1 & $12,819,000$ & 123380 & 103.89 \\
\hline 2 & $11,444,000$ & 95638 & 119.65 \\
\hline 3 & $6,885,000$ & 74095 & 92.92 \\
\hline 4 & $15,871,000$ & 134516 & 117.98 \\
\hline 5 & $18,028,000$ & 178006 & 101.27 \\
\hline 6 & $22,865,000$ & 189278 & 120.80 \\
\hline
\end{tabular}

When dividing the historical funding component by the annual ECWUs of an ED, a cost in Australian dollars (AUD) per ECWU is calculated. This equation has been applied to a selection of hospitals and the dollar amount per ECWU shown. Table 6 identifies that the ED in Hospital 3 has less resource allocation funding than Hospital 6 (92 AUD per ECWU versus 120 AUD per ECWU).

Another proposed function for the ECWU includes estimating or allocating approximate numbers of staff required for each discipline within the ED. In Table 8 we used a hypothetical scenario using the de-identified hospitals from Table 5. The total ECWUs have been divided by the number of FACEMS (Fellows of Australasian College for Emergency Medicine) or equivalent (Senior Medical Officers) currently 
employed within the department. The figure derived is the number of ECWUs per FACEM/ SMO employed. This equates to the workload of one FACEM/ SMO within that ED.

Table 7: Number of ECWUs per FACEM/ SMO in the de-identified Queensland hospitals

\begin{tabular}{|cccc|}
\hline Hospital & ECUs & FACEM/SMO & $\begin{array}{c}\text { Total } \\
\text { ECUs/FACEM- } \\
\text { SMO }\end{array}$ \\
\hline 1 & 123380 & 10.5 & 11750.4 \\
\hline 2 & 95638 & 8.5 & 11251.5 \\
\hline 3 & 74095 & 4 & 18523.7 \\
\hline 4 & 134516 & 12.5 & 10761.3 \\
\hline 5 & 178006 & 7.2 & 24723.0 \\
\hline 6 & 189278 & 17.6 & 10754.4 \\
\hline
\end{tabular}

This table shows that Hospital 3 has a greater number of ECWUs and therefore greater workload per FACEM/SMO than hospital 2. Hospital 5 appears to be really understaffed in comparison with the others. This above exercise can be repeated for nursing staff, allied health and administrative staff.

\section{Discussion}

This paper reports the methodology and concept of a new ED workload tool using a novel unit, the ECWU. It proposes a simple method to compare ED workload and resource needs between different hospitals. As yet there are no other methods for comparing like with like within the ED work environment. We envisage that the 
ECWU tool has several potential applications in different settings and could include most of the staffing disciplines within the ED.

While the ECU is a simple and easy to use tool, there are a number of limitations of the proposed tool. Firstly, validating this new tool will be challenging and requires the government to accept the tool as a way of informing funding and staffing allocation. In addition, should the tool be implemented by governments to influence funding of EDs, there would be a requirement to take into account projected figures for the following year's population growth and attendances within the individual triage categories. This has previously been considered in the Queensland Health Systems Review. ${ }^{14}$ Secondly, there are no benchmarks for appropriate levels of staffing for emergency departments using ECUs. However this tool may assist to highlight any shortfall of staffing numbers and skill-mix in individual departments. This aspect has the potential to inform funding bodies of the need for increased funding to provide a fair and equitable distribution of resources and staffing.

One limitation in the methodology of this proposed model is that we did not account for type of hospital or geographical location of the hospital. University teaching hospitals may require different staffing than rural or urban hospitals. Future versions of this model could involve adding a weighting to certain types of hospital to reflect the need for increased cost relating to the teaching hospital environment. Furthermore, some remote hospitals are mainly staffed by GPs. They do not operate on a triage system due to the low numbers of presentations. They also require a certain amount of resource allocation in order to function regardless of their low presentation rates. 
It is also worth noting that costs per triage category also vary across each state most likely related to differing staffing pay scales and costs of equipment. This could be accounted for in the model by using state figures when calculating ECWU's .

While access-block is known to impact on the workload of a department ${ }^{15}$ it was also not taken into account by this tool. These parameters may be included in a more detailed future version of the tool.

Other impacts on workload not included within the ECWU tool were the hospital EDs' use of short stay units or emergency medical units. These units can create an increased workload for the ED but are not standard across all EDs. Short stay units will increase the length of stay in an ED and increase the staffing requirements across all disciplines. Calculations involving whether a patient is still currently an ED patient or a hospital patient when admitted to these units and their funding strategies vary considerably across each institution. This component may need to be taken into account separately when considering funding and staffing allocation. It will be necessary to further explore this matter in future revisions of this model.

Retrieval or transfer of patients may also impact on the workload of an ED. Some departments may need to dispatch staff to transfer patients to another hospital or from an accident scene. This activity increases overall workload in the ED. 
Lastly, we could not control for individual hospital practice in allocating triage scores. Definitions of the admitted patient may vary across different EDs, and this may impact triage category presentation numbers. It is assumed that any discrepancy in ATS between hospitals will be partly compensated by disposition status in the ECWU tool. If an ED 'over-triages', the admission rate for this ATS will be lower compared to the state or national average, and if a department 'under-triages', a higher than average admission rate is expected. However, despite this there exists an opportunity for Emergency departments to over triage in an effort to improve their budgets or staffing allocation.

\section{Conclusion}

The ECWU is a workload calculation tool that may be useful for ED staffing and resource allocation. It has the potential to be developed further to allow for other factors that impact on ED workload such as access block, observation units and other ancillary services that an ED may provide. 


\section{References}

1. Duffield C, Conlon L, Kelly M, Catling-Paull C, Stasa H. The emergency department nursing workforce: Local solutions for local issues. Int. Emerg. Nurs. 2009, doi:10.1016/j.ienj.2009.10.003.

2. Australasian College for Emergency Medicine. The Australasian triage scale. Emerg. Med. 2002; 14: 335-36.

3. Department of Health and Ageing. National Hospital Cost Data Collection. Cost Report Round 12 (2007-2008).

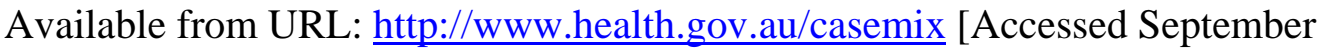
2009].

4. Fitzgerald GJ. The National Triage Scale. Emerg.Med.1996; 8: 205-06.

5. Fullam C. Acuity-based ED nurse staffing: a successful 5-year experience. J. Emerg. Nurs. 2002; 28: 138-40.

6. Korn R, Mansfield M. ED overcrowding: An assessment tool to monitor ED registered nurse workload that accounts for admitted patients residing in the emergency department. J. Emerg. Nurs. 2008:34-5.

7. Beveridge R, Clarke B, Janes L, et al. Canadian emergency department triage and acuity scale: implementation guidelines. Can J Emerg Med 1999;1(3 Suppl).

8. Murray M, Bullard M, Grafstien E, CTAS and CEDIS National Working Groups. Revisions to the Canadian emergency department triage and acuity scale implementation guidelines. Can J Emerg Med 2004;6(6):1.

9. Anderson CK, Zaric GS, Dreyer JF, Carter MW, McLeod SL. Physician workload and the Canadian Emergency Department Triage and Acuity Scale: the 
Predictors of Workload in the Emergency Room (POWER) Study. Can J Emerg Med. 2009 Jul;11(4):321-9.

10. Ma W, Gafni A, Goldman RD. Correlation of the Canadaian Paediatric Emergency Triage and Acuity Scale to ED resource utilization. Am J Emerg Med. 2008 Oct;26(8):893-7.

11. Dong SL, Bullard MJ, Meurer DP, et al. Predictive validity of a computerized emergency triage tool. Acad Emerg Med. 2007 Jan;14(1):16-21.

12. EDIS Production Support Team. Emergency department standard definitions, terminology and staff data entry. Brisbane: Queensland Health; 2007.

13. Casemix Funding Model 2009-2010 Technical Paper. Casemix, Costing and Allocation Team. Available from URL: http://www.casemix.health.qld.gov.au [Accessed September 2009].

14. Queensland Health Systems Review. Final Report. 2005. Available from URL: http://www.health.qld.gov.au/health_sys_review/final/qhsr_final_report.pdf [Accessed December 2009].

15. American College of Emergency Physicians. Emergency department crowding: high impact solutions. ACEP Task Force Report on Boarding; 2008. 